\title{
Editorial for the special issue:
} "Novel Solutions and Novel Approaches in Operational Research"

\author{
co-published with the Slovenian Society INFORMATIKA - Section for Operational \\ Research (SSI-SOR)
}

\section{Samo Drobne}

University of Ljubljana, Faculty of Civic and Geodetic Engineering, Ljubljana, Slovenia

\section{Ksenija Dumičić}

University of Zagreb, Faculty of Economics and Business, Zagreb, Croatia Lidija Zadnik Stirn

University of Ljubljana, Biotechnical Faculty, Ljubljana, Slovenia

\section{Abstract}

This special issue of Business Systems Research (SI of the BSR) is co-published by the Slovenian Society INFORMATIKA - Section for Operational Research (SSI -SOR) and highlights recent advances in Operations Research and Management Science (OR /MS), with a focus on linking OR /MS with other areas of quantitative and qualitative methods in a multidisciplinary framework. Eleven papers selected for this SI of the BSR present improvements and new techniques (methodology) in Operations Research (OR) and their application in various fields of economics, business, spatial science, smart mobility, higher education, human resources, environment, agriculture and social networks.

Keywords: interdisciplinary research, operations research, risk and uncertainty, statistical analysis, machine learning, multi-criteria decision making, big data, location-allocation, fuzzy logic, graph theory, project management, system dynamics, simulation methods.

Citation: Drobne, S., Dumičić, K., Zadnik Stirn, L. (2020). "Editorial for the special issue: "Novel solutions and novel approaches in Operational Research", Vol.1 1, No. 2, 1-6. DOI: 10.2478/bsrj-2020-0011

\section{Editorial process}

The term operations research (OR), or often management science (MS), refers to a scientific approach to decision making that attempts to determine how best to design or operate a system, usually under conditions that require the allocation of resources in business language (Winston, 2003). OR is a decision support discipline and as such is concerned with the development of systems to help decision makers to solve problems and make decisions. Within decision support topics, OR offers data analysis, simulation, modelling techniques, and software tools (Mladenić et al., 2003; Rubio et al., 2014).

The applications of $O R$ in real word problems are very numerous and in very different fields such as industrial engineering, management, economics, production, government, health care, transport, geographic information systems, scheduling, marketing, inventory, environment and others (Cochran et al., 2011). The applications of OR allow complex 
problems to be structured transparently and flexibly in a realistic context, introducing both quantitative (e.g. financial ratios) and quantitative criteria into the evaluation process (Figueira et al., 2005).

OR has had an important impact on improving the efficiency of organizations and has contributed to increasing productivity and social welfare. The International Federation of Operational Research Societies (IFORS) and the Association of European Operational Research Societies (EURO) are umbrella organizations for OR societies worldwide, representing more than 50 national societies, including Slovenian Society INFORMATIKA Section for Operational Research (SSI-SOR). The main events organized by SSI-SOR are the international symposia. The 15th International Symposium on Operations Research, called SOR'19, took place in Bled, Slovenia, from 25 to 27 September 2019. SOR'19 was the scientific event in the field of Operations Research, another in the traditional series of biennial international OR conferences, organized in Slovenia by SSI -SOR. The main objective of SOR'19 was to promote the knowledge, interest and education of OR in Slovenia, in Europe and worldwide, in order to build the intellectual and social capital that is essential for maintaining the identity of $O R$, especially in a time when interdisciplinary cooperation is proclaimed to be significantly important for solving problems in the current challenging times. Furthermore, the SSI -SOR agreed to cooperate with different disciplines, i.e. to strike a balance between the depth of theoretical knowledge in OR and the understanding of theory, methods and problems in other areas inside and outside OR. About 115 participants from research institutes, universities, governmental institutions, private and public companies from 16 countries around the world took part in SOR'19. 106 papers were presented, written by 203 authors and co-authors. The papers were accepted after a blind peer review process by two independent reviewers selected from SOR'19 Program Committee and by reviewers appointed by SSI -SOR.

At SOR'19 it was agreed that the special issue (SI) of the BSR would be published, so the Call for Papers for this SI was already published during this symposium in Bled in September 2019. The call was addressed to the participants of SOR'19 as well as to other researchers from the area of OR. The submitted papers should present developments and new techniques in OR methods/models and their practical applications in the fields of economics, business, finance, organization, management, social sciences, environment, transport and other fields.

Several contributions have been received. Some of them are extended journal versions of short SOR'19 papers from proceedings (Zadnik Stirn et al., 2019). Each submission to the SI of the BSR was first blind reviewed by the guest editors and then by two independent experts. Eleven contributions were selected for this special issue of the BSR. They owe their practical orientation and the consistent emphasis on model formulation and modelling. In addition, they go beyond a mere presentation of algorithms and reinforce the features and coverage of the latest developments in optimization, simulation and decision analysis.

The selected contributions deal with developments and techniques in OR and their practical application in the fields of business, economics, spatial science and location, environment and social sciences. The topics covered in the selected contributions represent interdisciplinary research and include, from a methodological point of view, multi-criteria decision making, fuzzy logic, neural networks, machine learning, predictive models, risk and uncertainty, and big data, while from an application perspective, they include business process modelling, organisational performance, strategic planning, financial applications, farm tourism, project management, pension expectations, mental wellbeing of employees, smart mobility, and higher education. The case studies origin from five countries: Portugal, Croatia, Slovenia, Norway and Hungary. 
The success of the SI of the BSR should be seen as a result of the joint efforts. The guest editors would like to thank the authors for their well-written contributions and the reviewers for their careful evaluation of the submissions and their thoughtful and constructive comments. Last but not least, the guest editors express their deep appreciation and gratitude to the editor-in-chief, Professor Mirjana Pejić Bach, PhD for her generosity, service and commitment in inviting us as guest editors of SI of the BSR.

\section{Contributions}

In accordance with the goals and editorial policy of BSR, the papers published in BSR are intended to present original theoretical and empirical advances in business and economic systems using a wide range of methodological approaches, primarily from the fields of operations research/analytics, management science and statistics. The eleven papers accepted by BSR for this SI fulfil these objectives.

In the first paper, entitled "Green Practices as a Path towards the Sustainability: Evidence from Portuguese Companies", Alves, Silva and Rodrigues consider the problem of the impact the companies cause on the environment and the society. They evaluate the level of environmental practices in micro, small, medium and large companies in the northern region of Portugal. The results reveal that the environmental issues are not yet properly addressed by treated companies; especially small companies face several berries to implement green actions, mainly those related to certification. The value of the paper is its contribution to new insights on how the handled companies have been implementing sustainable practices, as well which practices they still need to develop to reach higher level of strategic, including financial, policies, and green and sustainable practices.

In the second paper, entitled "Comparison of Two Network-Theory-Based Methods for detecting Functional Regions", authors Drobne, Garre, Hontoria and Konjar analyse two methods for modelling functional regions based on graph theory. In the case study of Slovenia, functional regions are calculated using the Walktrap algorithm and a proprietary, so-called, chain approach. They analyse the quality of the two regionalisation methods using the fuzzy set theory with its revised approach. After the results of the case study of Slovenia, the authors concluded that the Walktrap algorithm functionally calculates more closed regions (more workers find work in the home region) than their chain method.

In the third paper, entitled "Deep Learning Predictive Models for Terminal Call Rate Prediction during the Warranty Period", Ferencek, Kofjač, Škraba, Sašek and Kljajić Borštnar present the problem of production companies to optimize their costs by minimizing the amount of funds to be reserved for product repairs during the warranty period. The research extends previous research by providing new insight into machine learning models, and offers additional understanding and validation on how data quality can affect those models. A few new predictive models based on different neural network architectures were developed. They were implemented on a case of a company in the field of home appliances. The results show that the best two models, deep neural network with 6 layers and a convolutional neural network differed in 1\% when predicting products' terminal call rate at 12 months.

In the next paper, entitled "Process Mining Contributions to Discrete-event Simulation Modelling", Jadrić, Ninčević Pašalić and Ćukušić state that the technological advance supported by information systems generates event logs which contain important information about the performance of a business process. Event logs are analysed using process mining techniques. The aim of the paper is to demonstrate and assess the potential of using process mining results as an input for discrete-event simulation modelling. The process mining procedure is employed on two datasets. The results show 
that process mining coupled with simulation models offers a suitable innovation environment. Practical implications in the smart parking case refer to better use of (public) resources, and point to the constraints in terms of the non-existence of specific event data, while In the case of higher education the results indicate a better prediction of student behaviour.

In the fifth paper, entitled "Portfolio Optimization Efficiency Test Considering Data Snooping Bias", Kresta and Wang are interested in the evaluation of strategy portfolio performance. The general approach for such evaluation is testing whether the strategy outperforms the benchmark. Such approach does not answer whether the overperformance is high enough to be considered as significant or whether it is just due to the randomness in data. Consequently, the authors propose an alternative approach based on the statistical test in order to evaluate the efficiency of the portfolio optimization strategies in view of the risk. The proposed approach is demonstrated on the Markowitz minimum variance model and the fuzzy probabilities minimum variance model. The results confirm that minimizing the variance of portfolio return in-sample also lowers the out-of-sample risk measures, and that the analysed strategies lower the risk of the portfolio during the market's decline in 94\% of the time in the 2009-2019 period.

Examining the mental wellbeing of employees, which is crucial for the long-term success of an organization, the authors Lipovac, Hajdu, Wie and Nyrud offer to the readers the sixth paper, entitled "Improving Mental Wellbeing in Organizations with Targeted Psychosocial Interventions. The presented research is looked at within individual-level interventions approach. The authors created a social network based on the data collected on 414 employees from 14 nursing homes in Norway where the nodes represent employees and edges describe the connections between the nodes, while the edge probability represents the connection strength between two nodes. The optimization environment computes the possible intervention scenarios and maximizes the overall wellbeing by minimizing the scores of the nodes (i.e., reversed wellbeing score) with the set of employees receiving the intervention. Interventions were provided to either contagious or randomly selected individuals. The results show that selectively targeting highly contagious individuals could be an efficient approach to improving wellbeing in organizations.

In the seventh paper, entitled "Selection of Project Managers: An Overview", the author Šiško Kuliš presents the problem of selecting a project manager. The paper is seen as an overview paper focusing on the existing studies/methodology. Project manager selection is concentrated on two approaches, a traditional one and on a modern based on multi-criteria decision making. The traditional approach is supported by structured interviews with the goal to project the candidate's behaviour in new and unknown circumstances. A new, modern, approach is based on psychometric testing and multicriteria methods, among which AHP has an important place. Current characteristics of the process of selecting project manager in Croatia are investigated. A special attention is devoted to the certification of managers as certificate is the basic criteria during project manager selection process. Important for the future research in the field is also the enormous list of up-to-date references.

Then follows the paper entitled "Pension Pessimism in the Young Generation: Basics or Instincts to Blame?", written by Kovács and Vaskövi, which is dealing with pension expectations that are so important for national economies, decision makers and individuals. The paper focuses Hungarian young generation's reasons regarding pessimistic attitude towards state pension expectations. A non-representative sample research is applied, resulting with 250 filled questionnaires. The surveys data were analysed using multidimensional statistical method, above all factor analysis, to test different hypotheses connected to financial literacy and gender differences in the 
pension scheme. The survey results were used also to make a comparative analysis with the ten biases, called instincts by Rosling (2018), in order to find the behavioural aspects lying behind the pessimistic attitude of most respondents. The overall results reveal general pessimism among Hungarian university students towards the social security benefits, due to the general pessimism in the 'overdramatic worldview'.

Further, the paper, entitled "A System Dynamics Approach to Decision- making Tools in Farm Tourism Development", Žibert, Rozman, Škraba and Prevolšek, establish that nowadays more and more agricultural holdings decide on developing market-oriented multi-function farming. The focus of their research is the development of rural tourism as one of socio-economic activities. The authors generate a qualitative causal loop model and a system dynamics model for the simulation of transition of farming establishments into tourist farms for the purpose of increasing income through the diversification. The validation of the model was upgraded with the Mean Squared Error auxiliary variable and Cumulative Mean Squared Error level element, using Powersim Solver with Genetic Algorithms. Different parameter values were used in eight simulation scenarios. The case study of Slovenia has been used in order to explore the scenarios for farm tourism development. It was discovered that transition to diverse farms relies on subsidies that are the main driving force for the transition.

In the tenth paper, entitled "Standard Project Risk Analysis Approach", Žužek, Rihar, Berlec and Kušar, state that the companies, if they want to stay effective, have to be able to adapt to the competitive environment and to essentially manage the risk. The authors consider different risk analysis methods/tools: qualitative, semi-quantitative, quantitative and a risk matrix which is in the quantitative case extended into a continuous graph, called a risk map. First, the major risk factors were identified and assigned to individual activities. The risk events were linked to their impacts, and the risk event probabilities, based on the experience with similar projects, were assessed. Finally, a risk map was generated. The results show that separate treatment of the risk event and the impact advantageous clarifies the cause and the effect, and thus allows for a separate planning of preventive and corrective measures.

In the last paper of this SI, entitled "An Investigation of Business Process Maturity: Report on Croatian Companies", Milanović Glavan, considers business process maturity which is an extensive version of business process orientation (BPO). Reaching higher stages of maturity means higher levels of process skills for the company while companies are viewed as a mixture of unified business processes. In every maturity level, it is of crucial importance to recognize and improve key turning points, i.e., maturity components that lead companies to the next level. The aim of the research was to provide a report on BPO maturity of Croatian companies and to stress the importance of key turning points. The level of maturity was investigated, the turning points were addressed by using cluster analysis method, and finally the most critical maturity components for each maturity level were determined. The results of the cluster analysis show that companies in Croatia have to improve all key turning points, with a special emphasis on the strategic view.

It might be concluded that the high quality and up-to-date challenging topics of the SI of BSR papers would be interesting to both, the scientific and the professional audience, since possible influence on theory and applications are visible.

\section{Guest Editors of SI BSR}

Ljubljana, Zagreb, October 2020

Samo Drobne

Ksenija Dumičić

Lidija Zadnik Stirn 


\section{References}

1. Cochran, J.J., Cox, L.A., Keskinocak, P., Kharoufeh, J.P., Smith, C. (201 1), "Wiley Encyclopedia of Operations Research and Management Science", Wiley, New Jersey.

2. Figueira, J., Greco, S., Ehrgott, M. (2005), "Multicriteria Decision Analysis", Springer, New York.

3. Mladenić, D., Lavrač, N., Bohanec. M., Moyle, S. (2003), "Data Mining and Decision Support", Kluwer, Boston.

4. Rubio, S., \& Jiménez-Parra, B. (2014), "Reverse logistics: Overview and challenges for supply chain management", International Journal of Engineering Business Management, 6, 12.

5. Winston, W. L. (2003), "Operations Research: Applications and Algorithms", Duxbury

6. Zadnik Stirn L., J. Žerovnik, M. Kljajić Borštnar, S. Drobne (2019): "The 14th International Symposium on Operational Research SOR'17, Proceedings", Bled, Slovenia, September 25-27, 2020. Ljubljana: Slovenian Society Informatika (SSI), Section for Operational Research (SOR).

\section{About the editors}

\section{Samo Drobne}

Member of Management Board of Slovenian Society INFORMATIKA - Section for Operational Research (SSI-SOR); Secretary of Slovenian Society INFORMATIKA - Section for Operational Research (SSI-SOR); Co-editor of several proceedings of the international symposia on operations research in Slovenia (Proceedings of SOR); Member of Editorial board of Geodetski vestnik - an open access journal of the Association of Surveyors of Slovenia; Member of Editorial board of Journal Communications - Scientific Letters of the University of Žilina. Editor can be contacted at samo.drobne@fgg.uni-lj.si

\section{Ksenija Dumičić}

Elected Member of International Statistical Institute (ISI) and Member of ISI Sections: International Association of Survey Statisticians (IASS) and International Association of Statistical Education (IASE); Member of: Royal Statistical Society (RSS), American Statistical Association (ASA), American Society for Quality (ASQ) and ASQ Statistics Division, Croatian Operational Research Society (CRORS) and Croatian Biometric Society (HBMD); Chair of Women in Statistics Section at Croatian Statistical Association (CSA); Management Committee Member of ISI Committee on Women in Statistics (CW-ISI); Editorial Board Member of: Croatian Operational Research Review (CRORR), Croatian Review of Economic, Business and Social Statistics (CREBSS) and Proceedings of the Faculty of Economics and Business in Zagreb; Program Committee Member of International Symposium on Operations Research in Slovenia - SOR, Slovenia. Editor can be contacted at kdumicic@net.efzg.hr

\section{Lidija Zadnik Stirn}

President of Slovenian Society INFORMATIKA - Section for Operational Research (SSISOR); Vice-president of Slovenian Society INFORMATIKA (SSI); Representative of SSI-SOR in International Federation of Operational Research Societies (IFORS); Representative of SSI-SOR in Association of European Operational Research Societies (EURO); Co-editor of Central European Journal of Operations Research (CEJOR); Co-editor of several proceedings of the international symposia on operations research in Slovenia (Proceedings of SOR); Member of Editorial board of Croatian Operational Research Review (CrORR). Editor can be contacted at lidija.zadnik@bf.uni-lj.si 